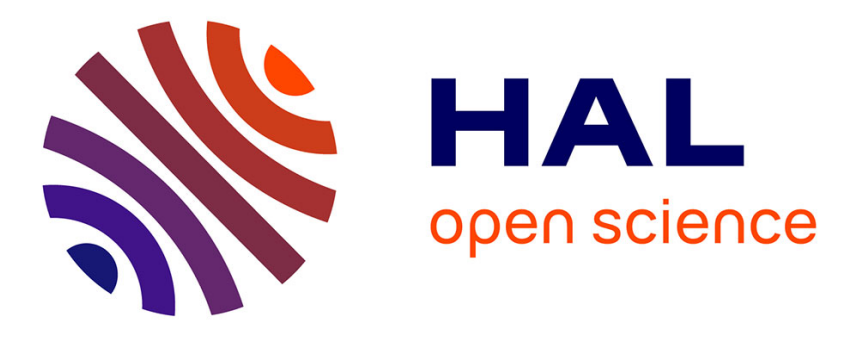

\title{
Oxidative degradation of polylactide (PLA) and its effects on physical and mechanical properties
}

\author{
Damien Rasselet, Alexandre Ruellan, Alain Guinault, Guillaume \\ Miquelard-Garnier, Cyrille Sollogoub, Bruno Fayolle
}

\section{- To cite this version:}

Damien Rasselet, Alexandre Ruellan, Alain Guinault, Guillaume Miquelard-Garnier, Cyrille Sollogoub, et al.. Oxidative degradation of polylactide (PLA) and its effects on physical and mechanical properties. European Polymer Journal, 2014, 50 (1), pp.109-116. 10.1016/j.eurpolymj.2013.10.011. hal-00977105

\section{HAL Id: hal-00977105 \\ https://hal.science/hal-00977105}

Submitted on 10 Apr 2014

HAL is a multi-disciplinary open access archive for the deposit and dissemination of scientific research documents, whether they are published or not. The documents may come from teaching and research institutions in France or abroad, or from public or private research centers.
L'archive ouverte pluridisciplinaire HAL, est destinée au dépôt et à la diffusion de documents scientifiques de niveau recherche, publiés ou non, émanant des établissements d'enseignement et de recherche français ou étrangers, des laboratoires publics ou privés. 


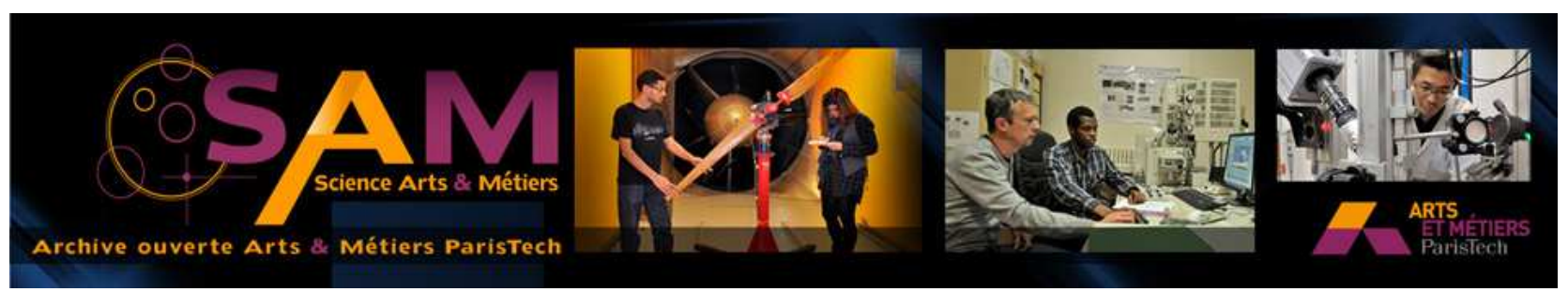

Science Arts \& Métiers (SAM)

is an open access repository that collects the work of Arts et Métiers ParisTech researchers and makes it freely available over the web where possible.

This is an author-deposited version published in: http://sam.ensam.eu

Handle ID: .http://hdl.handle.net/10985/7957

\section{To cite this version :}

Damien RASSELET, Alexandre RUELLAN, Alain GUINAULT, Guillaume MIQUELARD-

GARNIER, Cyrille SOLLOGOUB, Bruno FAYOLLE - Oxidative degradation of polylactide (PLA) and its effects on physical and mechanical properties - European Polymer Journal - Vol. 50, $n^{\circ} 1$, p.109-116 - 2014 


\title{
Oxidative degradation of polylactide (PLA) and its effects on physical and mechanical properties
}

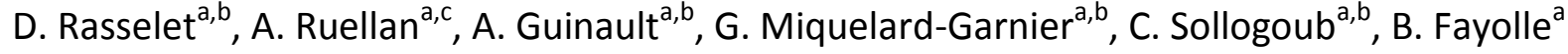 \\ a : PIMM, Arts et Métiers ParisTech, 151 boulevard de l'Hôpital, 75013 PARIS, France \\ b : P-2AM, CNAM, 292 rue Saint-Martin, 75003 Paris, France \\ c : UMR1145 Ingénierie Procédés Aliments, AgroparisTech, 1 Av des Olympiades, F-91744 \\ MASSY.
}

Abstract

The thermo-oxidative degradation of polylactide (PLA) films was studied between 70 and $150^{\circ} \mathrm{C}$. It was shown that the oxidative degradation of PLA leads to a random chain scission responsible for a reduction of the molar mass. These molar mass changes affect $\mathrm{Tg}$ and the degree of crystalllinity, and it was found that Tg decreases according to the Fox-Flory theory whereas the degree of crystallinity increases due to a chemicrystallization process. A correlation between molar mass and strain at break during oxidation has been established: PLA displays a brittle behaviour when $M_{n}$ falls below $40 \mathrm{~kg} \cdot \mathrm{mol}^{-1}$ in agreement with relationships linking the critical value for embrittlement with the molar mass between entanglements.

Corresponding author: bruno.fayolle@ensam.eu

Keywords: Polylactic acid, polylactide, ageing, thermo-oxidation, embrittlement. 


\section{INTRODUCTION}

In the market of biodegradable polymers, polylactide (PLA) is undoubtedly one of the most promising candidates for further developments since it is not only biodegradable but also produced from renewable resources, such as sugar beet and corn starch [1]. PLA can be found under several forms depending on the enantiomeric ratio of the lactic acid group, namely PLLA (poly-L-lactic acid), PDLA (poly-D-lactic acid) and the most common one, PDLLA (poly-D,L-lactic acid), each PLA having specific properties.

Some of the PLA properties are comparable to the ones of conventional polymers. Ease of processing, mechanical properties (especially Young's modulus), glass transition temperature higher than room temperature and high transparency thus make PLA a promising material for packaging and other industrial applications [2]. Therefore, understanding the oxidation and thermal degradation of this polymer is of great importance, because they affect directly the physical state of the polymer and as a consequence its performance in use.

PLA performance in terms of durability are limited by multiple chemical ageing mechanisms such as thermal decomposition [3-5], hydrolysis [6-8], photo oxidation $[9,10]$, natural weathering [11] and thermo oxidation at high temperature $[12,13]$. Due to biodegradable applications, numerous studies dealing with hydrolytic ageing are available (see for instance reference [8]). However, no studies of ageing in atmospheric conditions in the absence of water and UV light have yet been conducted. As a consequence, we focus our study only on the oxidative degradation of PLA induced at moderate temperatures (i.e. below the PLA melting temperature).

Concerning kinetics of thermal degradation in air of PLA, different assessments of activation energy $\left(E_{a}\right)$ can be found in the literature. It is noteworthy that these experimental data are based on thermogravimetric measurements (TGA mainly). For example, Gupta and Deshmukh reported the degradation process above $150^{\circ} \mathrm{C}$ as being a single-stage type, with lactide as the major decomposition product. From isothermal TGA measurements in air, they found the overall activation energy $\left(E_{a}\right)$ of the degradation to be $104-125 \mathrm{~kJ} / \mathrm{mol}[14,15]$. McNeill and Leiper investigated the degradation of PLLA under both controlled heating conditions and isothermal conditions in an inert atmosphere. A first-order kinetic model 
enabled them to obtain an apparent activation energy of $119 \pm 4 \mathrm{~kJ} \cdot \mathrm{mol}^{-1}$ in the temperature range $240-270^{\circ} \mathrm{C}[16,17]$. Babanalbandi et al. reported $E_{a}$ values for PLLA using isothermal gravimetric analysis over the temperature range $180-280^{\circ} \mathrm{C}$ under nitrogen and air. Their results showed that $E_{a}$ for isothermal weight loss rate was between 72 to $103 \mathrm{~kJ} / \mathrm{mol}$ depending on degradation conversion [18]. Their hypothesis was that the PLLA degradation process followed complex kinetics, even at low conversion. Liu et al. reported that the degradation of PDLLA at processing temperatures $\left(170^{\circ} \mathrm{C}-200^{\circ} \mathrm{C}\right.$ under air or nitrogen) follows a random chain scission mechanism, with two to three degradation stages depending on atmosphere and exposure temperature (higher than $160^{\circ} \mathrm{C}$ ). They identified that $E_{a}$ changes (from $137 \mathrm{~kJ} / \mathrm{mol}$ to $142 \mathrm{~kJ} / \mathrm{mol}$ ) can be associated with the various degradation stages [19].

As already stated, all these data are obtained from experiments conducted at higher temperatures than the melting temperature of PLA $\left(160^{\circ} \mathrm{C}\right)$. Therefore, it is possible that others mechanisms and kinetic behaviour take place during degradation below $160^{\circ} \mathrm{C}$, i.e. in the solid state. Moreover, TGA experiments are often questionable to follow degradation since volatile products can have multiple sources (thermal decomposition, oxidation...).

The main purpose of the present work is to investigate thermal oxidation of commercial PLA (containing a small fraction, typically 5\%, of D-lactide groups) below its melting temperature. The final objective of this work is to build a model based on the following steps:

1. Understanding the oxidation mechanism at temperatures below $160^{\circ} \mathrm{C}$.

2. Building a kinetic model to simulate and predict macromolecular modifications independent of exposure temperature and oxygen pressure.

3. Establishing relationships between macromolecular modifications and physical/mechanical properties valid for all exposure conditions to predict the lifetime of the PLA in dry applications.

In this study, we first identify the chain scission kinetics at different temperature conditions. Thus, to the best of our knowledge, this study constitutes the first systematic investigation concerning the ageing of PLA under thermal oxidation below its melting temperature. Second, physical properties such as glass temperature and degree of 
crystallinity are characterized during the oxidation process in order to correlate these properties with the molar mass changes. Finally, taking into account that tensile properties are strongly dependant on the molar mass, mechanical behaviour is characterized to establish a master curve linking properties at break and molar mass during oxidation independent of any ageing conditions.

\section{EXPERIMENTAL}

1) Material and preparation of films

The poly(D,L-lactide) (PDLLA) used in this study was supplied by NatureWorks (U.S.A.). The selected grade 2002D had a D content of 4.25\% [20], $M_{w}=209,000$ g.mol ${ }^{-1}, M_{n}$ $=101,000$ g.mol ${ }^{-1}$, polydispersity index: $M_{w} / M_{n}=2.07$ (obtained from SEC measurements) and a melting temperature of $155^{\circ} \mathrm{C}$ (obtained from DSC measurements).

Prior to processing, pellets were dried at $90^{\circ} \mathrm{C}$ under dried air for $4 \mathrm{~h}$ to remove water traces. Films were prepared from these pellets by extrusion using a single-screw MAPRE extruder of $30 \mathrm{~mm}$ in diameter with a barrel of length-to-diameter (L/D) ratio of 33 and a three-section screw. The temperature profile of the six zones of the screw was 180-180$180-185-190-190^{\circ} \mathrm{C}$ and the speed screw was set at $40 \mathrm{rpm}$. A flat die of $200 \mathrm{~mm}$ in width heated at $190^{\circ} \mathrm{C}$ and a chill roll Haake equipment were used to manufacture films having 145 $\mathrm{mm}$ in width and approximately $40 \mu \mathrm{m}$ in average thickness. The roll temperature and the roll speed were fixed, respectively, at $25^{\circ} \mathrm{C}$ and $\approx 1 \mathrm{~m} / \mathrm{min}$.

\section{2) Ageing conditions}

The films were exposed in an oven under air at constant temperature of 70, 100, 130 or $150^{\circ} \mathrm{C}$. Other smaller specimens $\left(3.5 \times 4 \mathrm{~cm}^{2}\right)$ were introduced in an autoclave at $100^{\circ} \mathrm{C}$ under an oxygen partial pressure of 30 bars. At chosen times, individual samples were removed from the oven or the autoclave to be characterized. 


\section{3) Characterization}

a) IR analysis

Infrared spectra in ATR mode were recorded with a FT-IR spectrometer Frontier (Perkin Elmer) and SPECTRA software for acquisition. Spectra were obtained using 64 scan summations and a $4 \mathrm{~cm}^{-1}$ resolution. The OMNIC software program was used to analyse the data.

b) Size exclusion chromatography (SEC)

The changes in molecular characteristics were obtained by size exclusion chromatography (SEC) using a Waters Co. equipment. It consisted of an isocratic pump (GILSON 307), a column oven (Waters Control Module II) at $35^{\circ} \mathrm{C}$, an automatic sample changer (Waters 717 plus Autosampler), a Refractive Index (RI) detector (Waters 2414) and a UV photodiode array detector (Waters 2998). The analysis was performed with THF as the eluent at a flow rate of $1 \mathrm{ml} \cdot \mathrm{min}^{-1}$. The PLA solutions were prepared in THF $160 \mathrm{mg}$ polymer $/ 3 \mathrm{ml}$ solvent). The Breeze software program was used for acquisition and analysis of the Waters data. Calibration of the SEC equipment was based on polystyrene standards (Shodex Standard from Showa Denko range 3070-778000 g.mol ${ }^{-1}$ ).

c) Differential scanning calorimetry (DSC)

The differential scanning calorimeter used to measure the thermal characteristics of the PLA was a Pyris 1 (Perkin Elmer). Calibration of the apparatus prior to the experiments was performed using an Indium standard. Samples of around $9 \mathrm{mg}$ were cut from the films and put in $40 \mu \mathrm{l}$ sealed aluminium pans. All the experiments were performed under dry $\mathrm{N}_{2}$ as a protective gas $(30 \mathrm{ml} / \mathrm{min})$. Three calorimetric scans were performed for each sample at a heating/cooling rate of $10^{\circ} \mathrm{C} / \mathrm{min}$. The first heating scan, in which the thermal history was suppressed, was performed from $0^{\circ} \mathrm{C}$ to $200^{\circ} \mathrm{C}$; the cooling scan went from $200^{\circ} \mathrm{C}$ to $0^{\circ} \mathrm{C}$ and the third and last heating scan from $0^{\circ} \mathrm{C}$ to $200^{\circ} \mathrm{C}$

The thermal characteristics - glass transition temperature $\left(T_{g}\right)$, cold crystallization temperature $\left(T_{c c}\right)$, enthalpy of cold crystallization $\left(\Delta H_{c c}\right)$, melting temperature $\left(T_{m}\right)$ and melting enthalpy $\left(\Delta H_{m}\right)$ - were determined from the first scan. The degree of crystallinity $\left(x_{C}\right)$ of the PLA samples was calculated using a enthalpy of fusion per mole of repeating unit of perfect crystal of infinite size (totally crystalline polymer) equal to $93 \mathrm{J.g}^{-1}$ [21]. 
d) Tensile tests

Tensile properties were obtained using a universal tensile machine (Instron model 4301) with dog bone shaped samples (NF ISO 37:2005-12 type 3 standard) cut in the films along the extrusion flow direction. Dog-bone useful cross-section was then 40 microns in thickness and $4 \mathrm{~mm}$ in width. Prior to tensile testing, film samples were conditioned at $23^{\circ} \mathrm{C}$ and $50 \% \mathrm{RH}$ (relative humidity) for $24 \mathrm{~h}$. Tensile tests were performed at a cross-head speed of $10 \mathrm{~mm} / \mathrm{min}$ at $23^{\circ} \mathrm{C}$ and $50 \% \mathrm{RH}$.

\section{RESULTS AND DISCUSSION}

1) Identification of oxidation products

Figure 1 shows the IR spectrum modifications of PLA films exposed to oxidation at $150^{\circ} \mathrm{C}$. The band assignements for neat PLA are made according to values provided in the literature [22]: $\delta_{\text {as }}\left(\mathrm{CH}_{3}\right)$ at $1454 \mathrm{~cm}^{-1}, \delta_{\mathrm{s}}\left(\mathrm{CH}_{3}\right)$ at $1383 \mathrm{~cm}^{-1}, \delta_{1}(\mathrm{CH})$ at $1359 \mathrm{~cm}^{-1}, \delta_{2}(\mathrm{CH})$ at $1292-1305 \mathrm{~cm}^{-1}$ and $v_{\text {as }}(\mathrm{COC})$ at $1208 \mathrm{~cm}^{-1}$. Only slight changes are observed which can be attributed to a secondary crystallization process, revealed by marked modifications of intensity at $955 \mathrm{~cm}^{-1}$ and $921 \mathrm{~cm}^{-1}$. Indeed, Meaurio has shown that during PLA crystallization, the intensity of the band at $955 \mathrm{~cm}^{-1}$, relative to the amorphous phase, decreases and that a new band appears at $921 \mathrm{~cm}^{-1}$ indicating the presence of $\alpha$ crystals [23].

Gardette [24] and Bocchini [25] showed that PLA photo oxidation by UV-light irradiation leads to the formation of carbonyl products, identified as anhydride functions, characterized by a new band at $1845 \mathrm{~cm}^{-1}$. Nevertheless in our case of thermal oxidation, we have not observed new bands, especially this expected band for anhydride functions at 1845 $\mathrm{cm}^{-1}$ (Figure 1). Only the splitting of the initial carbonyl bands at $1745-1754 \mathrm{~cm}^{-1}, 737-754$ $\mathrm{cm}^{-1}$ and $692-711 \mathrm{~cm}^{-1}$ could be observed. However, the modifications in the $690-760 \mathrm{~cm}^{-1}$ region could also be explained by crystallinity changes which lead to other conformations of the polymer. The splitting of the initial carbonyl bands at $1745-1754 \mathrm{~cm}^{-1}$ could also be linked to the presence of new carbonyl bonds, not belonging to anhydride functions, formed during the PLA oxidation. All the modifications previously described are independent of the exposure temperature. Because of the chemical structure of the PLA, no carbonyl associated with the chain scission mechanism can be detected by FTIR (as is commonly done for 
polyolefines), because the intrinsic PLA carbonyl band is located in the $1700-1750 \mathrm{~cm}^{-1}$ region. Nevertheless, we can assume that PLA thermal oxidative degradation follows the mechanism shown in Figure 2. This hypothesis is made considering that the tertiary $\mathrm{CH}$ bond shows the lowest dissociation energy and that hydroperoxides $(\mathrm{POOH})$ contribute mainly to the oxidation initiation step and follow a close-loop mechanism [26]. To complete this mechanism, we have to consider that the structure of the $\mathrm{PO}^{\circ}$ radical can decompose by three possible $\beta$-scissions as shown in Figure 3. Among these ones, only path (1) does not produce anhydrides [24].

2) Molecular weight modifications

Figure 4 shows the changes in $M_{n}$ and polydispersity index $(P I)=M_{w} / M_{n}$ of PLA samples as a function of time during thermal oxidation at 100,130 and $150^{\circ} \mathrm{C}$. It appears that $M_{n}$ decreases with time for all samples suggesting strongly that a chain scission mechanism is largely predominant during oxidation (Figure 4a). One can notice that this mechanism does not exhibit an induction period, i.e. the oxidation starts from the beginning of the exposure. As expected, the rate of molar mass reduction increases with the temperature.

However, PI displays a relative stability with values between 2 and 2.5 independent of the ageing temperature (Figure $4 b$ ). In addition, no secondary peaks can be observed in the SEC chromatograms.

This strongly suggests that chain scissions occur randomly along the polymer macromolecules under thermo-oxidative conditions and validates that degradation is homogeneous through the film thickness. As a result, the molar mass drop can be attributed to a chain scission process, knowing that if depolymerisation process had occurred at the same time, this latter mechanism would have caused a remarkable $P /$ increase in time.

According to Saito [27], the number of chain scissions, s, given in $\mathrm{mol} / \mathrm{kg}$, can be expressed by the following equation:

$$
s(t)=\frac{1}{M_{n}(t)}-\frac{1}{M_{n}(0)}
$$


where $M_{n}(0)$ is the molar mass of the initial sample and $M_{n}(t)$ is the molar mass of the aged sample after an exposure time $t$.

Figure 5 represents the evolution of $s$ with the exposure time during thermal oxidation at $70,100,130$ and $150^{\circ} \mathrm{C}$. For comparison with hydrolytic degradation, molar mass measurements have been performed on PLA samples exposed at $70^{\circ} \mathrm{C}$ in water; the related chain scission number is also included in the same Figure 5.

First, by comparing ageing in air and in water at $70^{\circ} \mathrm{C}$, we can conclude clearly that the hydrolysis ageing can be neglected in air. At temperatures higher than $100^{\circ} \mathrm{C}$ in air, ageing mechanism is undoubtedly the oxidation.

To confirm that oxidation is the predominant mechanism of degradation, exposures under 30 bars of oxygen have been performed. Figure 6 shows the change of $M_{n}$ for PLA samples exposed at $100^{\circ} \mathrm{C}$ under an oxygen partial pressure of 0.2 and 30 bars. One can observe $M_{n}$ of all the films exposed to an oxygen partial pressure of 30 bars decreased significantly from the beginning of exposure, the chain scission rate being dependent on the oxygen concentration into the polymer. By assuming, as a first approach, that the oxidation rate is proportional to the chain scission rate, this result suggests that oxidation occurs in air and that the oxidation rate depends on oxygen pressure as in many polymers such as polypropylene [28].

Analysing the data shown in Figure 5, it is possible to assess the activation energy for the oxidation rate assuming that the oxidation rate is proportional to the chain scission rate. $E_{a}$ is then found close to $60 \mathrm{~kJ}^{\mathrm{mol}}{ }^{-1}$, which is significantly lower than values reported in the literature (see Introduction). Whereas degradation kinetic are mainly assessed by following weight loss (TGA measurements), we believe that such measurements have to be used with caution to predict PLA lifetime at low temperatures.

\section{3) $T_{g}$ and degree of crystallinity changes}

DSC measurements on PLA films exposed to oxidation at 100,130 and $150^{\circ} \mathrm{C}$ were also performed. It was observed that, whatever the exposure temperature, $T_{g}$ tends to decrease while the melting temperature as well as the degree of crystallinity tend to increase during the oxidation process (Figure 7). It is noteworthy that DSC thermograms (not shown here) do not display any shoulder or secondary peak during the oxidation process. 
Indeed, melting temperature values increase slightly with exposure time suggesting that this secondary crystallization linked to the molar mass decrease is not due to new crystals but rather to a crystallite thickening process [29].

The $T_{g}$ decrease can be attributed without any doubt to the chain scission process occurring during oxidation. Indeed, in the case of linear polymers, $T_{g}$ and number average molecular weight are linked by the Fox-Flory relationship [30] $T_{g}=T_{g, \infty}-k / M_{n}$, where $k$ (K.kg. mol ${ }^{-1}$ ) is the Fox-Flory constant and $T_{g, \infty}$ the glass transition temperature of a PLA having an infinite molar mass.

$T_{g}$ is plotted as a function of $1 / M_{n}$ in Figure 8 for all temperatures of exposure: a linear correlation is found confirming the Fox-Flory approach can be applied to predict $T_{g}$ changes during a chain scission process. According to Figure 8 and the Fox-Flory relationship, we can estimate a $T_{g, \infty}$ value of about $55^{\circ} \mathrm{C}$, which is in agreement with values proposed elsewhere for PLA [31].

According to the DSC thermograms, it can be observed that an annealing process occurs during the first stage (roughly 48 hours) of exposure at 100,130 and $150^{\circ} \mathrm{C}$, because of the well-known PLA cold crystallisation. After this first stage, crystallinity increases slowly with the oxidation process. In other words, crystallinity increases until about $40 \%$ in these first hours of exposure to reach a regime where crystallinity is then only driven by the chain scission. Figure 7 shows the change in crystallinity for PLA samples exposed to oxidation at 100,130 and $150^{\circ} \mathrm{C}$ as a function of chain scission number. It is obvious that the crystallinity increases regardless of exposure temperature. As a result, one can conclude that the degree of crystallinity is mainly governed by the chain scission process.

The phenomenon linking crystallinity and chain scission is often called chemicrystallization. Indeed, in semi-crystalline polymers the chain scission process occurs only in the amorphous phase by freeing new chain segments. These segments can then integrate the crystalline phase if they have sufficient mobility, which is the case in the rubbery state. In our case, this process are likely to occur since exposure temperatures were well above $T_{g}$, knowing PLA $T_{g}$ are usually measured between 47 and $60^{\circ} \mathrm{C}$ (Figure 8).

Fayolle et al. [32] have proposed a relationship linking chemi-crystallization and chain scissions processes, introducing the concept of crystallisation yield. This can be defined as the number $y$ of monomer (or elementary chain segment) units entering the crystalline phase per scission event. The instantaneous value $y$ (unitless) of this yield is given by [32]: 


$$
y=\frac{1}{M_{m}} \frac{d x_{c}}{d s}
$$

where $M_{m}$ is the molar mass of the monomer unit $\left(M_{m}(P L A)=72 \mathrm{~g} / \mathrm{mol}\right), x_{c}$ is the degree of crystallinity, and $s$ is the number of chain scission event per mass unit.

Figure 7 allows us to assess the term $\mathrm{d} x_{c} / \mathrm{d} s$ from the slope of the straight line. One can thus notice that the degree of crystallinity increases regardless of exposure temperature, and consequently the term $\mathrm{d} x_{c} / \mathrm{d} s$ can be considered as a constant. Using equation (2), an average value of 44 for $y$ is found, as reported in Table 1 . It is noticeable that this value is very close to the ones obtained for others polymers such as PE [33] or POM [34] (see Table 1). As a result, a prediction for the degree of crystallinity is now possible based on a chain scission kinetic model.

\section{4) Embrittlement process}

Figure 9 shows the changes in strain at break for PLA films exposed to oxidation at 100,130 and $150^{\circ} \mathrm{C}$. The strain at break before annealing is not reported in this figure since its value is close to $20 \%$. It is noteworthy that this value, though higher than what is usually reported in the literature for PLA [35], has already been observed by several groups especially for extruded samples [36, 37]. During the oxidation process, strain at break values drop with increasing exposure time and reach a value close to zero after a time depending on the exposure temperature, about 150, 250 and 500 hours for 150,130 and $100^{\circ} \mathrm{C}$ respectively. One can also notice that a higher exposure temperature results in a faster decrease in the tensile properties.

It is well known that mechanical properties at break of vitreous amorphous linear polymers are strongly dependent on the molar mass. In the case of semi-crystalline polymers having their amorphous phase in the rubbery state, these properties are dependent not only on the molar mass but also on the crystalline morphology (degree of crystallinity, amorphous layer thickness) [32]. In the case of PLA, we have seen that during oxidation the molar mass decreases whereas the degree of crystallinity increases, both aspects being intimately linked. However, in our study, tensile tests have been performed at room temperature, i.e. at much lower temperature than $\mathrm{T}_{\mathrm{g}}$ (even considering its drop during 
oxidation). As a result, strain at break values have been measured on oxidized PLA having its amorphous phase in the glassy state. In a first approach, we propose to investigate a possible correlation between strain at break values with the degree of crystallinity or with the molar mass (see Figures 10 and 11 respectively).

Looking at figure 10, the embrittlement process cannot be correlated to the crystallinity increase (Figure 10) since the scattering of the data does not allow the building of a master curve. As a result, the degree of crystallinity does not appear to be the main parameter which governs PLA embrittlement.

Figure 11 shows strain at break as a function of number average molar mass $\left(M_{n}\right)$ for the three exposure temperatures. Indeed, it has been proposed that $M_{n}$ is the relevant average molar mass to correlate with the failure properties for glassy linear polymers [38]. Here, the strain at break decreases sharply when $M_{n}$ decreases until a critical value of about $40 \mathrm{~kg} / \mathrm{mol}$ where it reaches a plateau value close to $1 \%$. A very good correlation is obtained independently of the considered temperature of exposure, which allows building a master curve linking molar mass with failure properties independent of chain scission kinetics.

From the master curve shown in Figure 11, the following aspects can be drawn. First, strain at break values can be predicted from molar mass values which could be simulated by a kinetic model for PLA oxidation. Consequently, knowing the chain scission kinetics, it will be possible to predict the embrittlement time, in other words the time when $M_{n}$ is below 40 kg.mol ${ }^{-1}$ : this time is around $150 \mathrm{~h}, 250 \mathrm{~h}$ and $500 \mathrm{~h}$ for the PLA aged at 150,130 and $100^{\circ} \mathrm{C}$ respectively. One can notice that this critical mass $M_{C}^{\prime}$ for complete embrittlement could also be applied in the case of hydrolytic ageing.

At last, the remaining question is the physical meaning of this value of $40 \mathrm{~kg} \cdot \mathrm{mol}^{-1} \mathrm{for}$ $M^{\prime}{ }_{C}$. For glassy amorphous polymers, it has been proposed that $M^{\prime}{ }_{C}$ is linked to the molar mass between entanglements. In order to predict $M^{\prime}{ }_{c}$ from the polymer structure, a parameter $q$ can be defined as $q=M^{\prime} d M_{e}$ where $M_{e}$ is the entanglement molar mass. For most of amorphous polymers, $q$ is about 5 [39]. On the other hand, for semi-crystalline polymers having their amorphous phase in the rubbery state, $q$ values are much higher (close to 50 [38]). For PLA, $M_{e}$ has been assessed close to $8 \mathrm{~kg} \cdot \mathrm{mol}^{-1}$ [40] leading to a $q$ value close to 5. From this point of view, it appears then that PLA at room temperature is a member of the glassy amorphous family. 


\section{CONCLUSION}

The thermal oxidation mechanism of PLA at low temperatures $\left(T<160^{\circ} \mathrm{C}\right)$ leads to a random chain scission process, responsible for the decrease of the PLA molecular weight as shown by SEC measurements.

Oxidation affects the physical and mechanical properties of the polymer, in agreement with some common behaviours observed during polyolefin oxidative ageing.

Thus, the glass transition temperature $T_{g}$ decreases according to the Fox-Flory theory whereas the degree of crystallinity increases due to a chemi-crystallisation process. This latter process links crystallinity and chain scissions following a crystallisation yield mechanism. The determined yield value is quantitatively comparable to the ones obtained for others polymers in thermal oxidation.

It is concluded that the strain at break decrease is clearly linked to the molar mass reduction during oxidation, independent of exposure temperature. PLA displays a brittle behaviour when $M_{n}$ is below $40 \mathrm{~kg} \cdot \mathrm{mol}^{-1}$, which is in agreement with relationships linking the critical value for embrittlement $\left(M_{c}^{\prime}\right)$ with the molar mass between entanglements $\left(M_{e}\right)$. 
Table 1: Chemicrystallization yield y of some polymers in thermal oxidation

\begin{tabular}{lcccc}
\hline \multicolumn{1}{c}{ Polymer } & Acronym & $\begin{array}{c}\text { Temperature } \\
\left({ }^{\circ} \mathrm{C}\right)\end{array}$ & $y$ & Reference \\
\hline Polylactide & PLA & $100-150$ & 44 & \\
Polyethylene & PE & $70-105$ & 45 & {$[33]$} \\
Polyoxymethylene & POM & 130 & $40-50$ & {$[34]$} \\
\hline
\end{tabular}




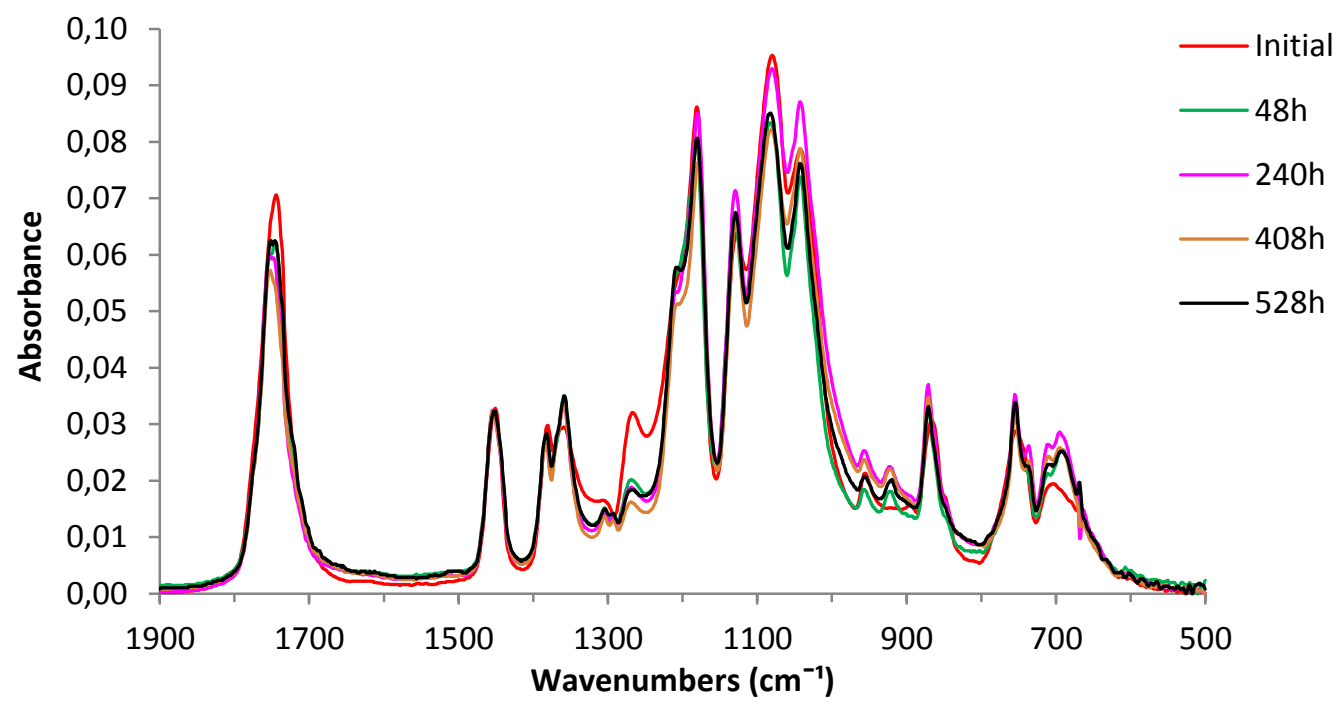

Figure 1: IR spectra of PLA films in ATR mode during thermal oxidation ageing at $150^{\circ} \mathrm{C}$, (normalization at $1453 \mathrm{~cm}^{-1}$ assigned to $\delta_{a s} \mathrm{CH}_{3}$ ). 


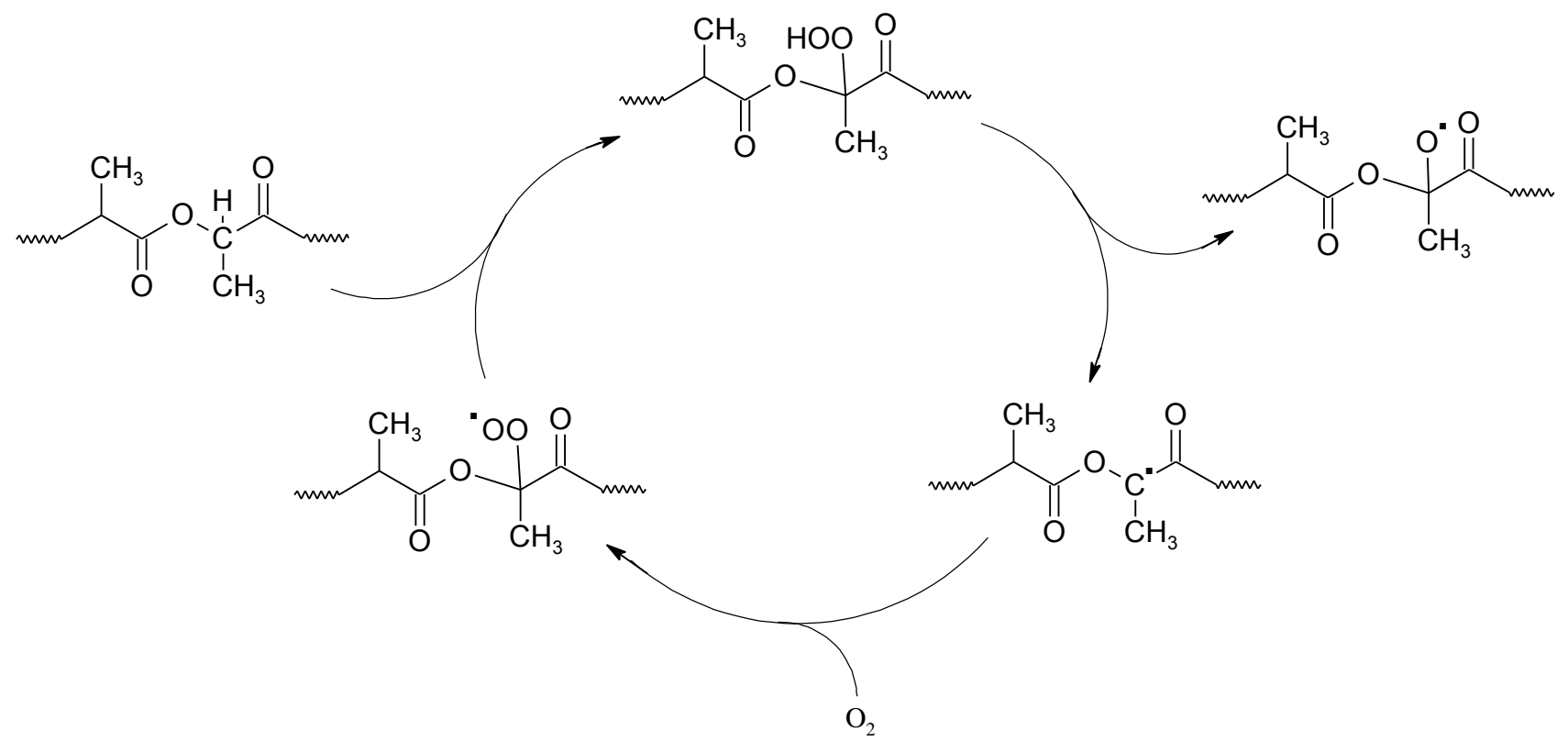

Figure 2: PLA oxidation mechanism.

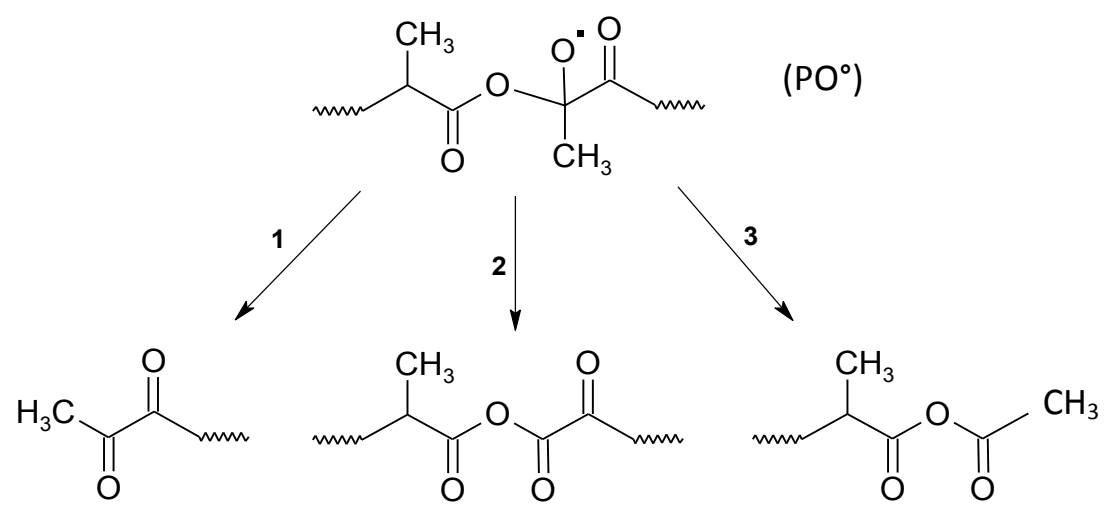

Figure 3: Possible 6-scissions of the $\mathrm{PO}^{\circ}$ radical according to [24]. 

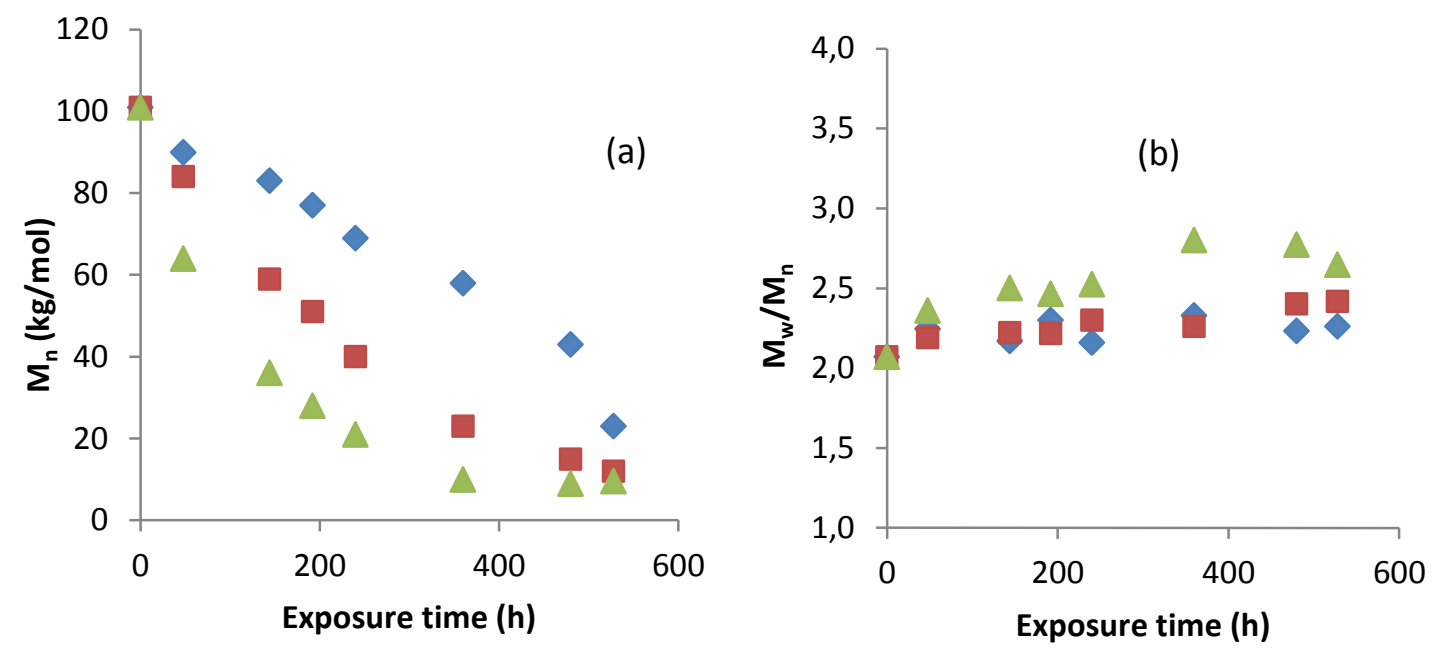

Figure 4: (a) $M_{n}$ and (b) polydispersity index changes of PLA samples aged at 100 ( ), 130 (ロ) and $150^{\circ} \mathrm{C}(\triangle)$.

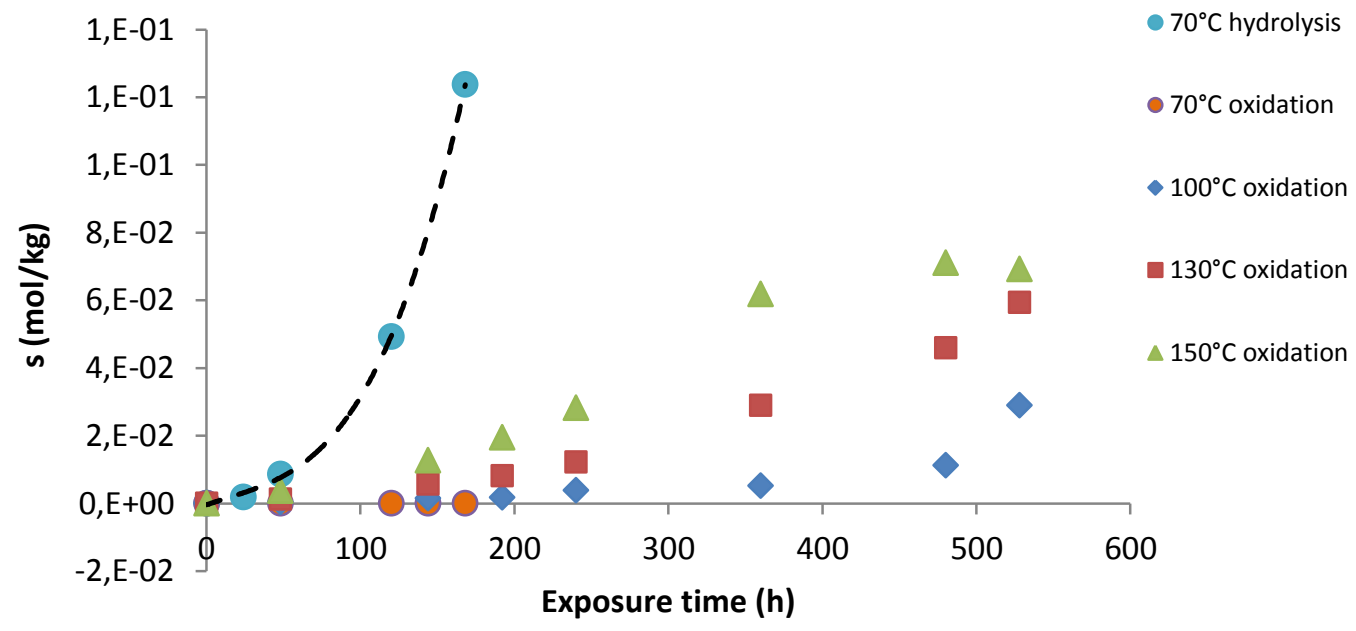

Figure 5: $s$ as a function of exposure time during thermal oxidation at $70,100,130$ and $150^{\circ} \mathrm{C}$ in comparison with hydrolysis at $70^{\circ} \mathrm{C}$. 


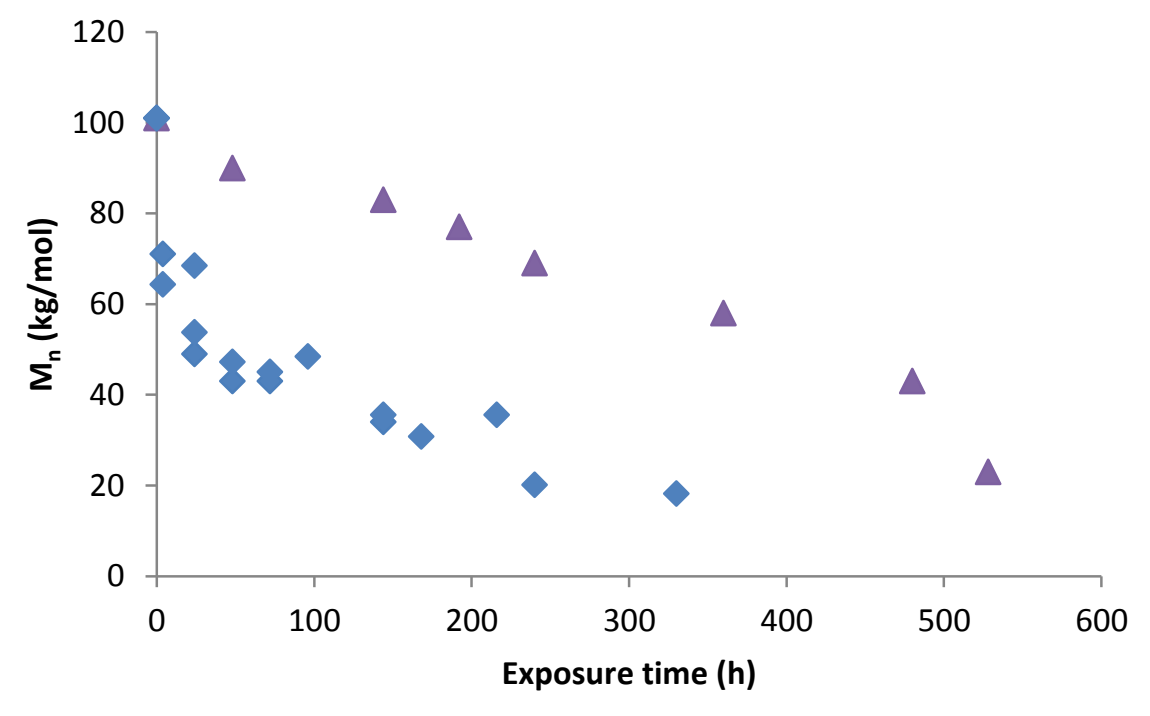

Figure 6: Evolution of $M_{n}$ as a function of exposure time exposed at $100^{\circ} \mathrm{C}$ under an oxygen partial pressure of $0.2(\mathbf{\Delta})$ and $30(\nabla)$ bars.

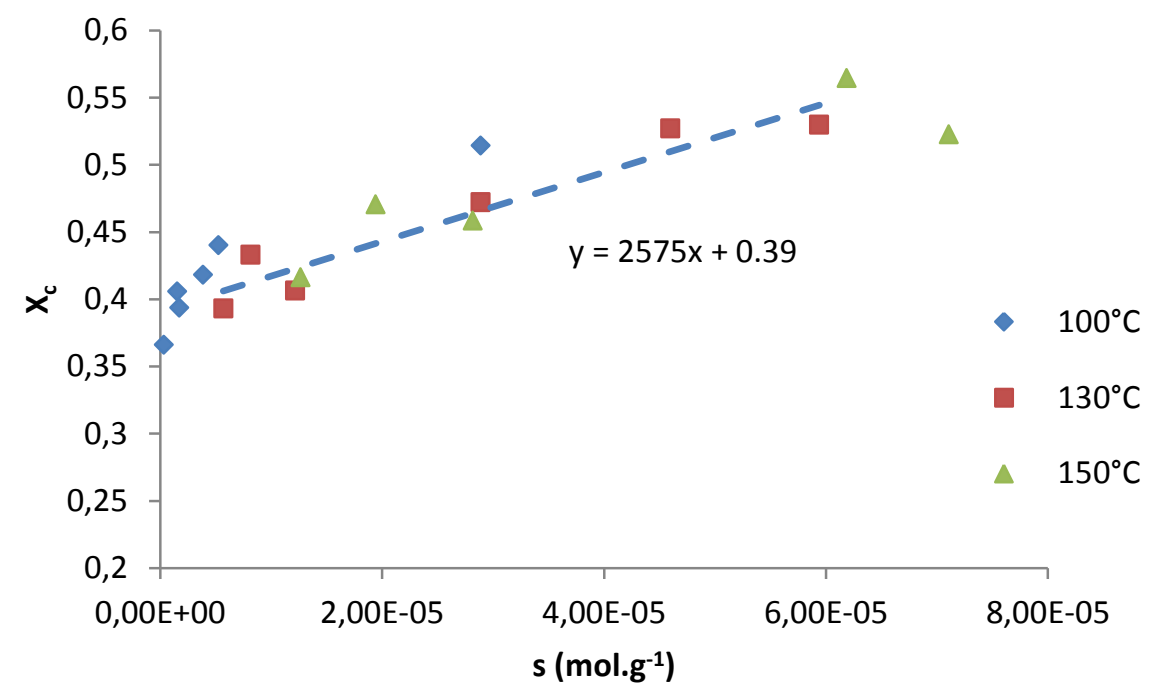

Figure 7: Degree of crystallinity as a function of the number of chain scission per mass unit. 


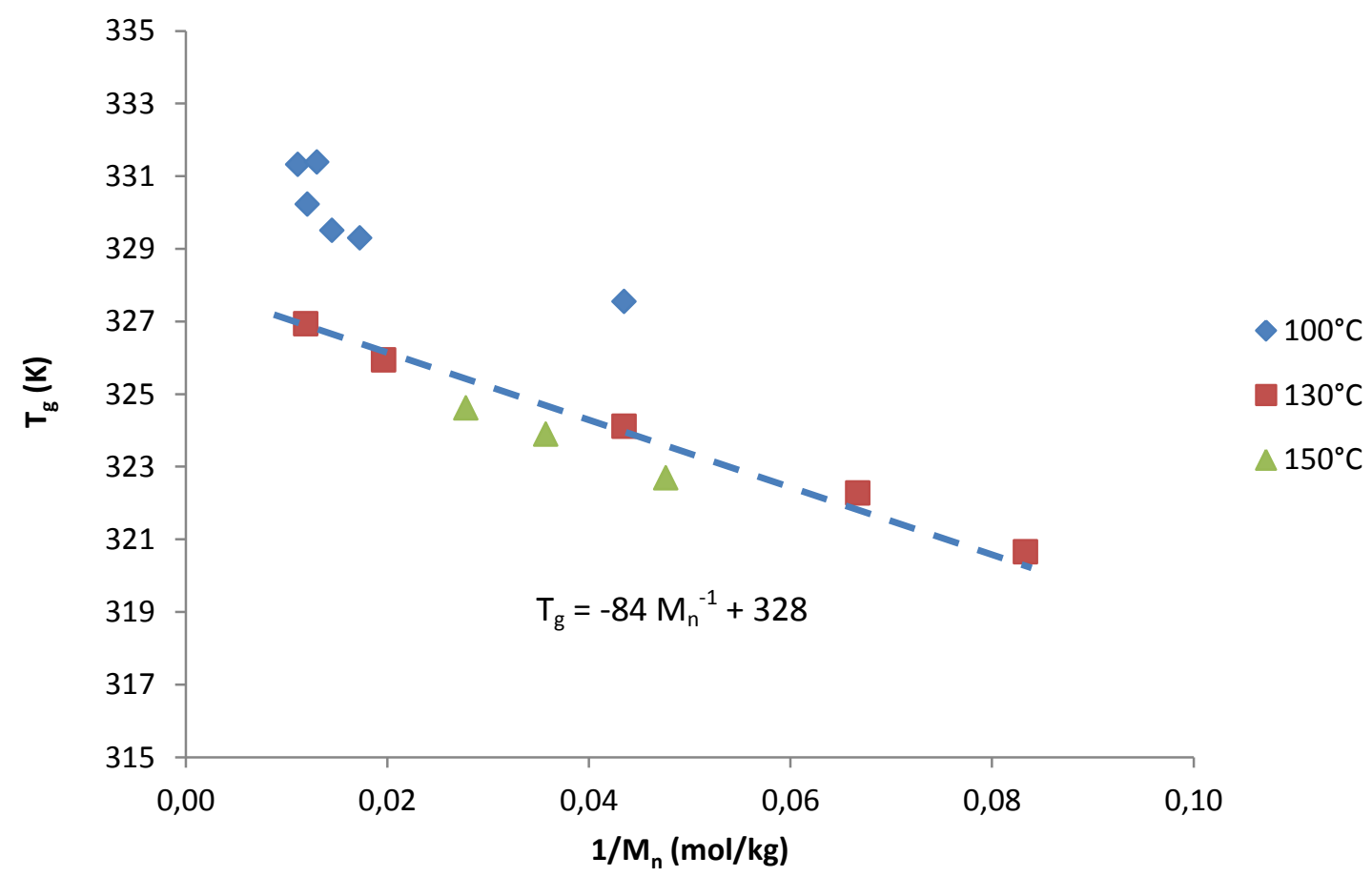

Figure 8: Glass transition temperature as a function of $\mathrm{M}_{n}^{-1}$ at 100,130 and $150^{\circ} \mathrm{C}$.

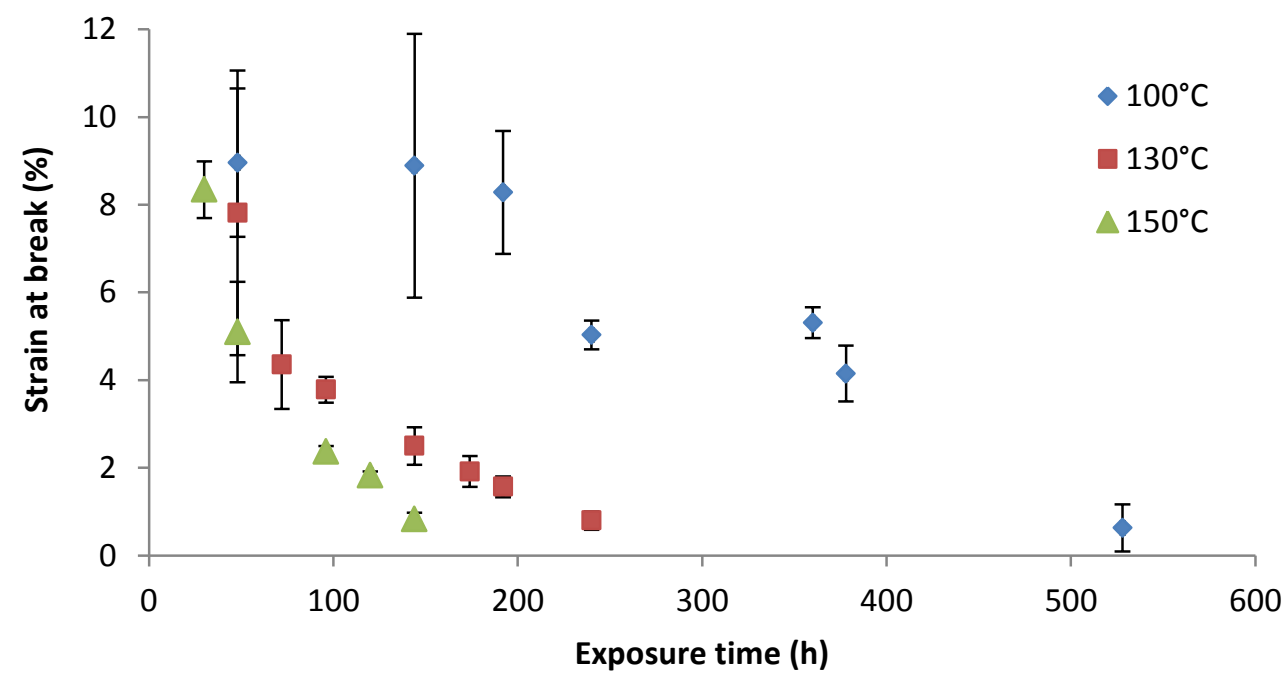

Figure 9: Strain at break changes as a function of exposure time during exposure at 100, 130 and $150^{\circ} \mathrm{C}$ under air. 


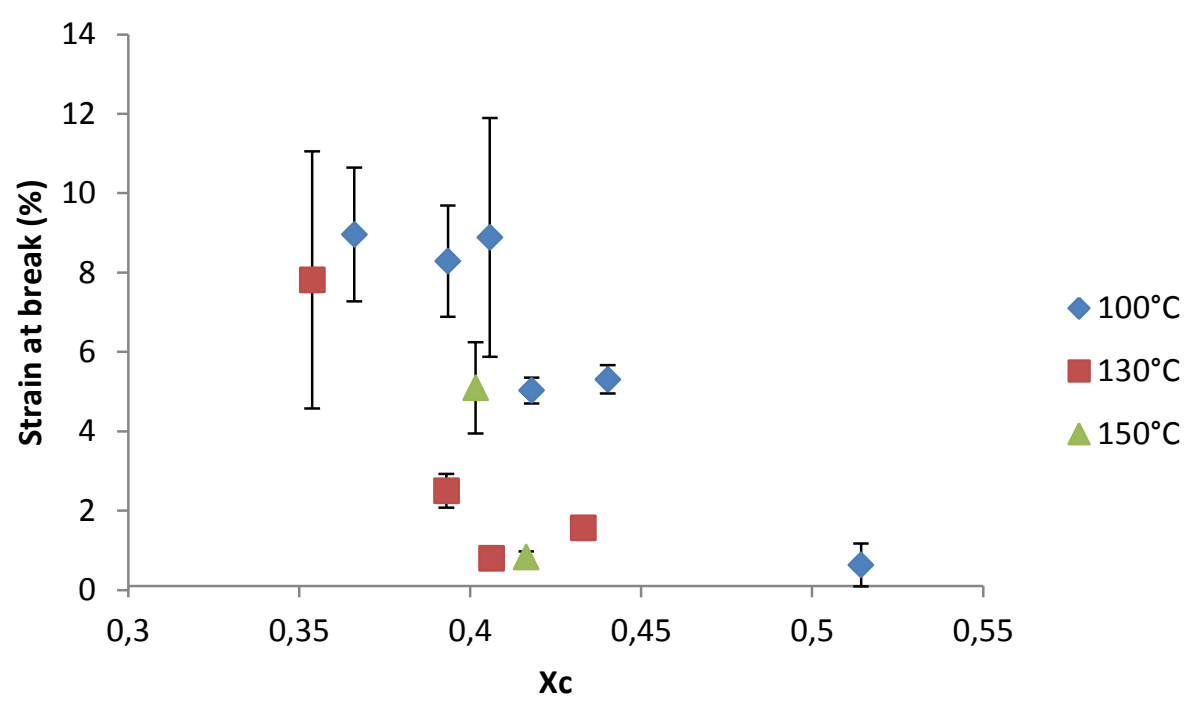

Figure 10: Strain at break as a function of degree of crystallinity during exposure at 100, 130 and $150^{\circ} \mathrm{C}$ under air.

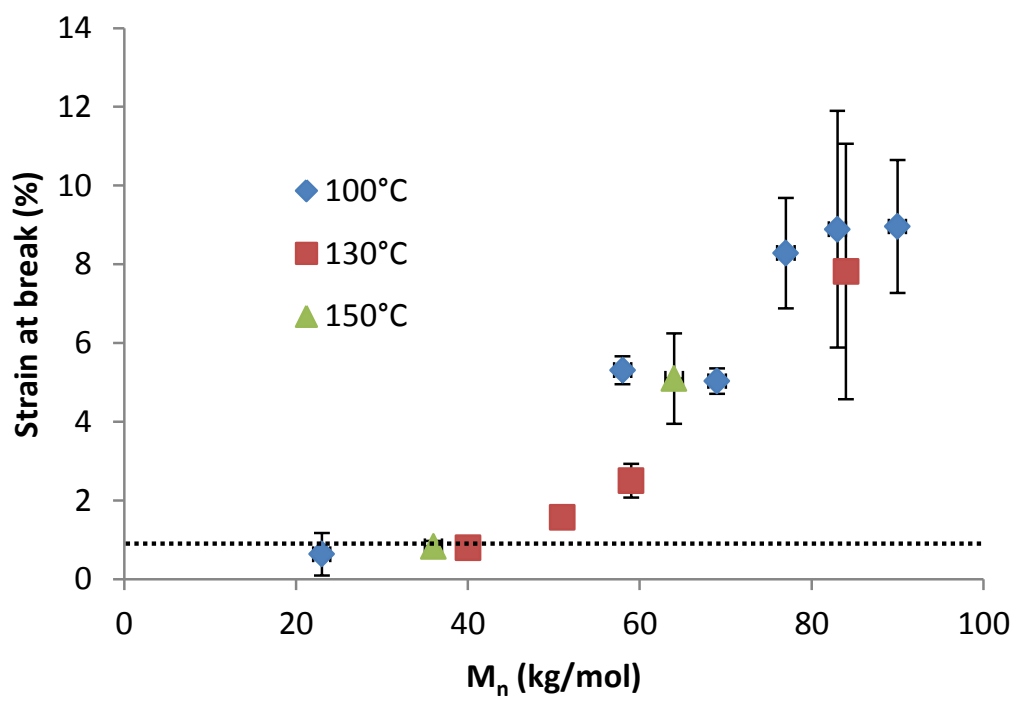

Figure 11: Strain at break as a function of number average molar mass $\left(M_{n}\right)$ during exposure at 100, 130 and $150^{\circ} \mathrm{C}$ under air. 


\section{Reference}

1. Auras RA, Lim L-T, Selke SEM, Tsuji H. Poly (lactic acid): synthesis, structures, properties, processing, and applications. Wiley, 2011.

2. Auras R, Harte B, Selke S. An overview of polylactides as packaging materials. Macromolecular bioscience 2004:4(9):835-864.

3. Aoyagi Y, Yamashita K, Doi Y. Thermal degradation of poly $[(R)-3$-hydroxybutyrate], poly [ $\varepsilon$ caprolactone], and poly [(S)-lactide]. Polymer Degradation and Stability 2002:76(1):53-59.

4. Kopinke FD, Remmler M, Mackenzie K, Möder M, Wachsen O. Thermal decomposition of biodegradable polyesters - II. Poly (lactic acid). Polymer Degradation and Stability 1996:53(3):329342.

5. Wachsen O, Platkowski K, Reichert KH. Thermal degradation of poly-L-lactid - studies on kinetics, modelling and melt stabilisation. Polymer Degradation and Stability 1997:57(1):87-94.

6. Hakkarainen M, Albertsson A-C, Karlsson S. Weight losses and molecular weight changes correlated with the evolution of hydroxyacids in simulated in vivo degradation of homo- and copolymers of PLA and PGA. Polymer Degradation and Stability 1996:52(3):283-291.

7. Li S, McCarthy S. Further investigations on the hydrolytic degradation of poly (DL-lactide). Biomaterials 1999:20(1):35-44.

8. Zhang X, Espiritu M, Bilyk A, Kurniawan L. Morphological behaviour of poly (lactic acid) during hydrolytic degradation. Polymer Degradation and Stability 2008:93(10):1964-1970.

9. Copinet A, Bertrand C, Govindin S, Coma V, Couturier Y. Effects of ultraviolet light (315 nm), temperature and relative humidity on the degradation of polylactic acid plastic films. Chemosphere 2004:55(5):763-773.

10. Tsuji H, Echizen $\mathrm{Y}$, Nishimura $\mathrm{Y}$. Photodegradation of biodegradable polyesters: $A$ comprehensive study on poly(l-lactide) and poly(E-caprolactone). Polymer Degradation and Stability 2006:91(5):1128-1137.

11. Zaidi L, Kaci M, Bruzaud S, Bourmaud A, Grohens Y. Effect of natural weather on the structure and properties of polylactide/Cloisite 30B nanocomposites. Polymer Degradation and Stability 2010:95(9):1751-1758.

12. Badia JD, Strömberg E, Ribes-Greus A, Karlsson S. Assessing the MALDI-TOF MS sample preparation procedure to analyze the influence of thermo-oxidative ageing and thermo-mechanical degradation on poly (Lactide). European Polymer Journal 2011:47(7):1416-1428.

13. Zhou $Q$, Xanthos $M$. Nanosize and microsize clay effects on the kinetics of the thermal degradation of polylactides. Polymer Degradation and Stability 2009:94(3):327-338.

14. Gupta MC, Deshmukh VG. Thermal oxidative degradation of poly (lactic acid), Part I: Activation energy of thermal degradation in air. Colloid \& Polymer Science 1982:260:308-311.

15. Gupta MC, Deshmukh VG. Thermal oxidative degradation of poly-lactic acid. Colloid and Polymer Science 1982:260(5):514-517.

16. McNeill IC, Leiper HA. Degradation studies of some polyesters and polycarbonatesâ-2. Polylactide: Degradation under isothermal conditions, thermal degradation mechanism and photolysis of the polymer. Polymer Degradation and Stability 1985:11(4):309-326.

17. McNeill IC, Leiper HA. Degradation studies of some polyesters and polycarbonates-1. Polylactide: General features of the degradation under programmed heating conditions. Polymer Degradation and Stability 1985:11(3):267-285.

18. Babanalbandi A, Hill DJT, Hunter DS, Kettle L. Thermal stability of poly (lactic acid) before and after $\gamma$-radiolysis. Polymer international 1999:48(10):980-984.

19. Liu X, Zou Y, Li W, Cao G, Chen W. Kinetics of thermo-oxidative and thermal degradation of poly (D, L-lactide)(PDLLA) at processing temperature. Polymer Degradation and Stability 2006:91(12):3259-3265. 
20. Niaounakis $M$, Kontou $E$, Xanthis $M$. Effects of aging on the thermomechanical properties of poly (lactic acid). Journal of Applied Polymer Science 2011:119(1):472-481.

21. Fischer E, Sterzel H, Wegner G. Investigation of the structure of solution grown crystals of lactide copolymers by means of chemical reactions. Kolloid-ZZ Polym 1973:251:980-990.

22. Kister G, Cassanas G, Vert M. Effects of morphology, conformation and configuration on the IR and Raman spectra of various poly (lactic acid) s. Polymer 1998:39(2):267-273.

23. Meaurio E, Lopez-Rodriguez N, Sarasua JR. Infrared spectrum of poly (L-lactide): application to crystallinity studies. Macromolecules 2006:39(26):9291-9301.

24. Gardette $M$, Thérias S, Gardette J-L, Murariu M, Dubois P. Photooxidation of polylactide/calcium sulphate composites. Polymer Degradation and Stability 2011:96(4):616-623.

25. Bocchini S, Fukushima K, Blasio AD, Fina A, Frache A, Geobaldo F. Polylactic acid and polylactic acid-based nanocomposite photooxidation. Biomacromolecules 2010:11(11):2919-2926.

26. Audouin L, Gueguen V, Tcharkhtchi A, Verdu J. "Close loop" mechanistic schemes for hydrocarbon polymer oxidation. Journal of Polymer Science Part A: Polymer Chemistry 1995:33(6):921-927.

27. Saito O. Effects of high energy radiation on polymers II. end-linking and gel fraction. Journal of the Physical Society of Japan 1958:13(12):1451-1464.

28. Richaud E, Farcas F, Bartoloméo P, Fayolle B, Audouin L, Verdu J. Effect of oxygen pressure on the oxidation kinetics of unstabilised polypropylene. Polymer Degradation and Stability 2006:91(2):398-405.

29. Baratian S, Hall ES, Lin JS, Xu R, Runt J. Crystallization and solid-state structure of random polylactide copolymers: poly (I-lactide-co-d-lactide) s. Macromolecules 2001:34(14):4857-4864.

30. Fox TG, Flory PJ. Second-order transition temperatures and related properties of polystyrene. I. Influence of molecular weight. Journal of Applied Physics 1950:21(6):581-591.

31. Mohanty AK, Misra M, Drzal LT. Natural fibers, biopolymers, and biocomposites. CRC Press, 2005.

32. Fayolle B, Richaud E, Colin X, Verdu J. Review: degradation-induced embrittlement in semicrystalline polymers having their amorphous phase in rubbery state. Journal of materials science 2008:43(22):6999-7012.

33. Viebke J, Elble E, Gedde UW. Degradation of polyolefin pipes in hot water applications: Simulation of the degradation process. Polymer Engineering \& Science 1996:36(4):458-466.

34. Fayolle B, Verdu J. Radiation aging and chemi-crystallization processes in polyoxymethylene. European Polymer Journal 2011:47(11):2145-2151.

35. Garlotta D. A literature review of poly (lactic acid). Journal of Polymers and the Environment 2001:9(2):63-84.

36. Boufarguine M, Guinault A, Miquelard-Garnier G, Sollogoub C. PLA/PHBV Films with Improved Mechanical and Gas Barrier Properties. Macromolecular Materials and Engineering, online 19 DEC 2012, DOI: 10.1002/mame.201200285.

37. Rathi S, Chen X, Coughlin EB, Hsu SL, Golub CS, Tzivanis MJ. Toughening semicrystalline poly (lactic acid) by morphology alteration. Polymer 2011:52(19):4184-4188.

38. Dai CA, Kramer EJ, Washiyama J, Hui CY. Fracture toughness of polymer interface reinforced with diblock copolymer: Effect of homopolymer molecular weight. Macromolecules 1996:29(23):7536-7543.

39. Donald AM, Kramer EJ. Effect of molecular entanglements on craze microstructure in glassy polymers. Journal of Polymer Science: Polymer Physics Edition 1982:20(5):899-909.

40. Cooper-White JJ, Mackay ME. Rheological properties of poly (lactides). Effect of molecular weight and temperature on the viscoelasticity of poly (I-lactic acid). Journal of Polymer Science Part B: Polymer Physics 1999:37(15):1803-1814. 